\title{
The Permanent Agriculture as a Means of Harmony between Nature Cycle and Human Being
}

\author{
Getulio Akabane ${ }^{1}$, José Roberto Kassai ${ }^{2}$, Antonio Cesar Galhardi ${ }^{3}$ \\ ${ }^{1}$ CPS Master Program/Yoko Civilization Research Centre \\ ${ }^{2}$ FEA-USP/Yoko Civilization Research Centre \\ ${ }^{3}$ CPS Master program; galhardi.
}

\begin{abstract}
The transformational spirit of evolution made us as human beings that shaping both the landscapes we inhabit and the universe of thought we entertain; it moves along our experiences, everything that we observe, reflect and engage. This research in exploratory case format was carried out on a farm in Bolivia through the research project used to detect the perceptions, opinions and feelings of the participants based on their experiences for decades with permanent agriculture. It tried to get a thorough understanding essences of the central phenomenon that follows the teaching guide modified the principle of permaculture Brown (2009) describing the essential properties of permanent agriculture. As result reflections, the agricultural system fundamental transformation requires a change of perspective and cultural awareness around human interrelations with the natural and industrial world. It also challenges people to take action in their communities to adopt sustainable agricultural practices that meet a human needs on a scale practice can transform way we view our relationship for both earth and each other's. And this success case with favorable performances especially in economic aspects shows a transition path for models that address the social, environmental and good governance.
\end{abstract}

Keywords: permaculture, sustainability, ecosystem, natural cycles,

\section{Introduction}

In this twenty-first century, all the world's living beings have inherited in an unprecedented way, major issues such as ecological disaster, extinction of species, the destruction of natural habitat, the pollution of air and river basins, the depletion of natural resources and disappearance of truly wild areas (NABHAN e TRIMBLE 1994; (RIETBERGEN, 2008; WILSON, 2002). Most of this disharmony arises from the mistaken human interaction with the organic systems and the cycle of nature (MERCHANT, 2005; METZNER, 1999; Sheldrake, 1994).

As the twentieth century was characterized by considerable progress in the areas of scientific exploration, technological and industrial growth and democratization of human rights, it also set unprecedented depletion of living resources of the planet (WILSON, 2002). Swimme e Berry (1994, p.17) point out that the fundamental heritage of human beings is an embedded story of transformation from the "Big Bang", the birth of the universe, and our very existence is a cumulative number of moments in a large unfolding of creative transformation. The transformation is perhaps the most consistent theme in terms of common ancestry between the history of the cosmos, where the evolutionary heritage of organic beings is characterized by extraordinary physiological and biological diversity. So it is not surprising that one of the most basic human tendencies is the attempt to understand this nature of transformation and the transformation of nature itself. Change of seasons, scientific experimentation, fluctuations between the heat and the cold, the creation of fire, the making and implementation of tools, celebrating the joys of life, while mourning the loss of the dead, being sick, metabolism in our own human body, the physical and psychological maturity, all require the close involvement with the transformation. The transformational spirit of evolution made us as human beings we are shaping both the landscapes we inhabit and the universe of thought we entertain; it moves along everything we experience, we observe, reflect, and engage.

The quality is the result of this processing; however, it requires a large extent of exposure and redirection, for the future of life on Earth does not react in a balanced way in this accounting balance. Berry (1977) warned that the many achievements of modern industrial cited as a great triumph of humanity, such as the spread of food crops on an industrial scale and the global distribution of commodities are factors which contribute towards the survival of organic beings. Wilson (2002) adds that the ecological time we live in is a result of hyperindustrialisation of the human being, as we drew from nature nonrenewable resources accelerating the disappearance of entire ecosystems and the extinction of thousands of species of millions of years old. Lovelock (2000b) studied the remarkable abilities that planet Earth has to auto settings creating the right conditions for life, abilities of self-regulation of the atmosphere, surface temperatures, and ecosystems, among others. It is thus possible to consider the ability of humanity as a global force similar to the planetary 
self-regulation. Given the right conditions and orientation, there is no reason why humans cannot play a role in healing the planet as a whole. That is, being the planet Earth an organism able to enact an immune response, it is quite conceivable to include the human species as part of this reaction.

Hawken (2007) reminds us that the human response to planetary healing is already underway. New strategies are emerging from the systems of government, civil society, agriculture and industry. In this sense, this research aims to explore through case study, the concept of permanent culture to support the creative impulses of civilized life to transform the detritus of human destruction into a functional representation. This is the farm Asano, an area of $4 \mathrm{ooom}^{2}$, located in the municipality of Samaipata, capital of Florida province in the department of Santa Cruz de la Sierra in Bolivia. It features a traditional agro ecosystem built by peasant agriculture that keep the natural ecosystems of the places and has a set of social and economic relations with the function of generating products for humans (GLIESSMAN, 2000).

For, to Berry (1988), humanity requires a complete reorientation of the commitment to become a marvel industrial world through strategies and tactics in a mutual effort to replace two of the biggest myths of modern industrial order: the conquest of nature as a single object, and the false infinite industrial growth for which threw itself with its development of ideas and progress. Thus, proclaims that human beings can sharpen their tools and focus on physical skills to rethink, re-contextualize and restructure the systems based on their cultural histories and philosophical views that drive deeper insights as dreams, visions of the future and relationships in the present, to enable the most powerful ecological myth to the seductive and addictive behavior vision of industrial society.

Historians assess the degree of environmental degradation by the rapid return on investment in agricultural production, the growth of population density and gradual restrictions of planting areas and job opportunities. In fact, continued population growth and the increasing reliance by the high productivity of crops quickly contributed to the growth and negative environmental impacts. Thus the growth of social desire to reduce environmental liabilities is proportional to the increase in the level of consciousness by the factors involved (CAPUTO, NAYAGA e SCARPA, 2013). Born e Purcell (2006) highlight the location movement of food systems with a focus on factors such as freshness, origin, safety culture, nutritional value and the reduction in time and distance are reducing the environmental impact of the product elements. These appeals to "local production" provide consumers create an image of the close and familiar food system (EDWARDS-JONES et al., 2008).

In fact, the regenerative agriculture fight for a closed loop system where the culture itself and the manpower come from within the agricultural system and the community as opposed to the industrial model that is an open system that requires the importation of chemical products, seeds and fossil fuels out of the agricultural system and the community (PEARSON, 2007). These aspects require the development of agricultural and social systems that really enrich and nourish the earth (soil, watersheds, flora, fauna and the overall health of the ecosystem) and adjacent communities (local economy, equitable access to healthy food, connection with nature.)

\section{Definition of Nature}

Sheldrake (1994) offers the appropriate starting point, pointing to the etymology of the word, as in European languages are female; physis in Greek, natura in Latin, la nature in French, die natur in German. In Latin, the word literally means "birth". The Greek word physis comes from the root Phu - whose main meaning is also associated with birth. Thus, the physical word comes from physics and since nature is natural, they have their origins in the maternity process. Sheldrake (1994) recognizes as many others seeking appropriate setting for words whose boundaries can be as ubiquitous and at the same time as illusory as the God or the Divine, that the definition of nature is multivalent.

Within a sentence, Nature can define material substance, in another, "innate character or disposition," as in the word human nature. However, Sheldrake (1994) explains that nature must be understood as the creative and regulatory power in operation in the physical world, the immediate cause of all its phenomena. And so, the nature means the natural or physical world as a whole. When nature in this sense is personified, it is Mother Nature, an aspect of the Great Mother, the source and sustainer of all life, and the womb to which all lives return.

In this sense, the human nature of behaviors, emotions, dreams, visions and aspirations are part of a whole that is nature, that is, the natural world. As for the wild nature, it refers to those very rare, fleeting and healthy remains, whole, unblemished extensions of land that have not been objects of attention of modern industry. This does not mean that the wild nature reflects the absence of humans. Certainly there are wild places where the human voice is rarely heard, but the world has known through relationships such as pastoral, indigenous and other harmonious forms between the earth and humans (ANDERSON, 2005; BERKES, 1999). Forests provide essential ecosystem services to humans, such as health and social services, diseases control, support lifestyle providing places and jobs, supply of water through the watershed protection, flow regulation 
and generation of precipitation water, food supply through natural products, stimulation of nutrient cycling and climate security (MEA, 2005).

\section{Conventional Agriculture and Sustainable}

Hansen (1996) points out conventional agriculture characterized by monocultures in large-scale capitalintensive and extensive use of chemical resources such as fertilizers, herbicides and pesticides while for Ikerd (1993), sustainable agriculture is characterized by small farms that depend on management of internal resources that limits commercial scale to reduce the negative ecological impacts of the handling of the land. Although the differences of applied technologies between conventional and sustainable agriculture are significant and where the major difference between the two approaches result in differences in agricultural philosophy (Ikerd, 1993) as:

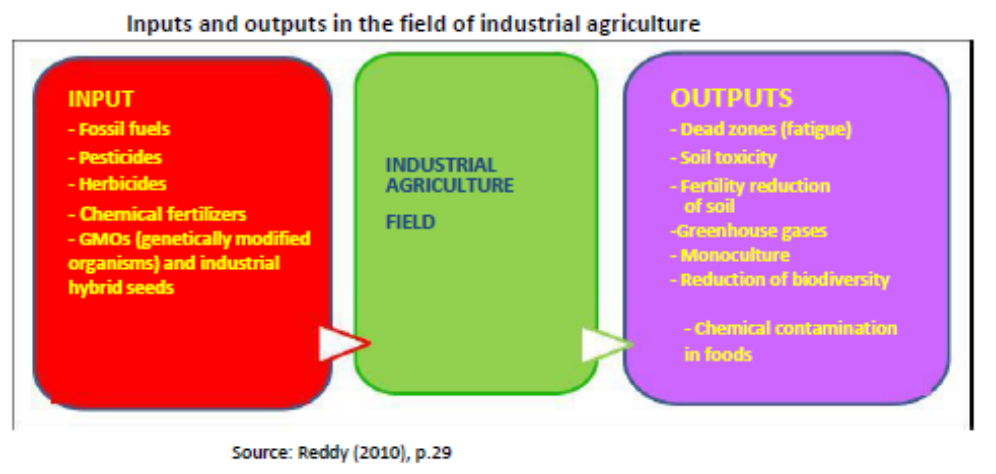

The objective of industrial development is to enhance human well-being by increasing the production of material goods and services ... While sustainable agriculture is based on a holistic paradigm or model of development that considers the production units as bodies decomposed in many sub-complex and inter-related organisms. People are seen as part of bodies or systems from which their welfare derives.

On the other hand, sustainable agriculture has been described as a broad term, an umbrella with various approaches including organic agriculture, ecological agriculture, regenerative agriculture, agroecology and permanent agriculture (permaculture) (HANSEN, 1996). The framework of sustainable agriculture incorporates social values such as decentralization, community integration, harmony with nature, self-reliance and preservation of agrarian culture (HANSEN, 1996). Yunlong e Smit (1994) describe the sustainable agriculture as a complex process that occurs in a triple environmental framework based on the biophysical environment, the socio-political environment and the economic and technological environment. The biophysical environment refers to the natural world within which operates agriculture, and is based on the need to maintain healthy ecological relationships. Ecological sustainability requires the preservation of physical conditions and the protection of biological diversity. The socio-political environment refers to the role that human and culture relationships have in influencing the way agriculture is practiced.

Thus, the social dimension of sustainability depends on continuous supply of current basic needs without decimating the environment for future generations. The economic and technological environment refers to feasibility and economic production of agricultural activities. Economic returns need to be sufficient to ensure the continuity of agricultural products. Yunlong e Smit (1994) observe the biophysical approach as politically acceptable partner, and technically and economically feasible for agriculture to be sustainable (p. 302). Ikerd (1993) also discusses the social dimension and proposes that sustainable agriculture be defined by its ability to conserve resources, protect the environment, produce efficiently and improve the quality of life for farmers and society which share it.

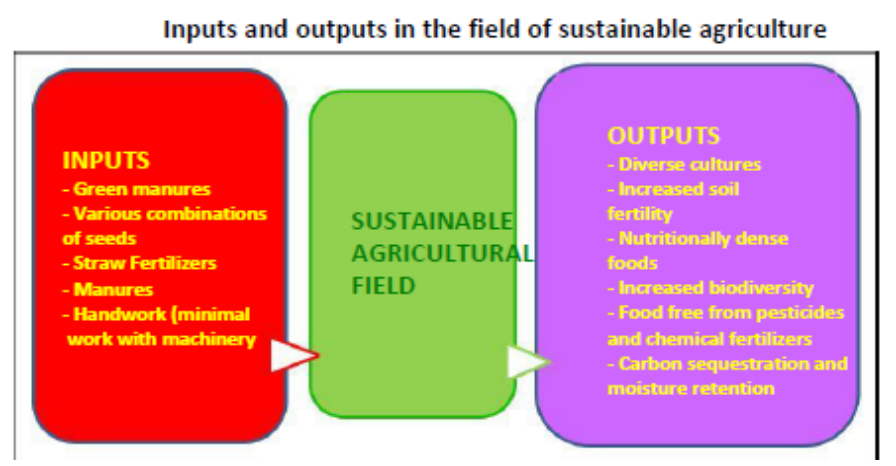

Source: Reddy (2010), p.37 
Systems that fail to conserve and protect its resource base, degrade productivity and eventually lose the ability to produce. In this way, systems that fail to protect the environment eventually produce more harm than good and lose their social utility and therefore are not socially sustainable. Farming systems that do not provide adequate and secure supplies, healthy food at a reasonable cost and otherwise improve the quality of human life are not politically sustainable. It is clear that sustainable agriculture goes beyond the limits of agronomy, incorporating social, political and economic processes to the science itself of food production. Buttel (1993) describes the incorporation of discipline of the social sciences such as sociology of agricultural sustainability. Thus, sociologists and other social scientists have played a significant role in "emergency, institutionalization and design of sustainable agriculture."

\section{Permanent Agriculture}

Certainly, there is nothing permanent in agriculture, a science based on cycles and the changing seasons. Mollison (1988) highlights the permanent agriculture as an association of science and practice based on observation and mimicry of healthy ecological relationships and patterns of nature forming a system-wide ethical approach and ecological design. It acts as a translator between many disciplines and brings together information from different areas. It can be described as a picture or pattern in which many forms of knowledge are mounted relative to each other. Permaculture is a synthesis of different disciplines.

Bell (2005) provides a broader definition as "a conscious design and maintenance of agriculture as production systems and preserving the diversity, stability and resilience of natural ecosystems." It is the harmonious integration of landscape with people who enjoy its food, energy, shelter and other material and nonmaterial sustainably.

To Jacke e Toensmeier (2005) it is a perennial polyculture of multi-purpose plants, ie an art to learn and imitate one of the healthiest ecosystems of the Earth, which is mature forests, where a diversity of microbial species, animal and plant which cooperate to form an interconnected network resilience and ecological harmony. Permaculture focuses on the transformation of human systems (agricultural, social and technological) to resemble healthy patterns of relationships with nature (MOLLISION, 1988; HEMENWAY, 2009).

The main concern is to create entire systems to take care of the land and preserve it for humanity, with sustainable ways to ensure the welfare of their children and harvest, while any surplus power come back to the health of the planetary system (MOLLISON e HOLMGREN, 1978). By this definition, permaculture design is an ecological science. That is, Mollison (1988) writes as:

"A conceptual mounting and material system, and strategic components in a pattern that works to benefit life in all its forms."

Because of its ethical dimension, permaculture not only has a partnership with nature but it can also be seen as an aspect of environmentalism (Mollison, 1988) and a direct response to modern agriculture and industry domination. Working against nature, depleting natural resources with reckless abandonment and subsequent poisoning of ecosystems with toxic waste are left as a byproduct of modern civilization (CAPRA, 1982; MERCHANT, 2005; MOLLISON, 1988; WILSON, 2002). Since permaculture is rooted in local cultures and ecosystems, the approach can be applied appropriately in all regions of the globe.

\section{Methodological Procedures}

This research in exploratory case study format treats the investigation project used to explore the perceptions, opinions and feelings of the participants based on their experiences on a particular phenomenon. It explores the experiences of people in order to obtain a thorough understanding of the essences of the central phenomenon (YIN, 2014). In this case the phenomenological research becomes appropriate to explore the harmony provided by permanent agriculture close to nature and the human being. For the research problem dictates the appropriate technique for the study (STRAUSS e CORBIN, 1998). This premise is supported by researchers in the statement of situational needs to drive the choice of research; if the approach is qualitative, quantitative, or mixed method (HITCHCOCK, NASTASI e SUMMERVILLE, 2010; JOHNSON, ONWUEGBUZIE and TURNER, 2007).

Thus, the qualitative research method is relevant to "explore and understand the meanings of individual or group attributes in a social or human problem" (CRESWELL, 2009, p.4). The method is most suitable for a problem-oriented in discovering the intricacies of a central phenomenon (CRESWELL, 2008; STRAUSS e CORBIN, 1998). Thus, the qualitative approach was appropriate for the study as a means to drive the objective of exploring the concept of permanent culture to support the creative impulses of civilized life to transform the detritus of human destruction into a functional representation. Thus, the methodological approach adopted is the "interpretive" or "hermeneutics", which can work in the delicate space between "human" and "natural," and that is to disclose aspects of the man-nature relationship in which the normal science simply cannot contemplate in its entirety. 


\section{Research Method}

As the first to distinguish the human from the natural sciences, van Manen (1990) and Dilthey (1883, 1988) said that the issues of thought, according to the infallible law, assigns predicates (through which all knowledge has its place) are elements that the natural sciences arrive only hypothetically to share with external reality, breaking and disassembling things considering that the human sciences find themselves as real units as experience of internal facts. The phenomenological interview method aims to discover and describe the experiences of life and processes of human experiments (van Manen, 2002). The harmonization of the study of the permanent agriculture with the cycle of nature and the human being is a search for meaning.

Thus, this research follows the modified teaching guide of Brown's principle of permaculture (2009) that matches their design applications as follows: Principle 1 - observe and interact: Its base is the culture based on the practice of interaction with nature of when to interfere or not, according to the existence of limitations and abundances of the ecosystem to meet our needs. The practice includes observation contemplation, mediation, photosynthesis, hiking and ecotourism and observation of the impact of the globe cycles that affect the culture.

Principle 2 - capture and storage of energy: All energy that comes from the sun and its waste can be recovered, stored and the surplus returned to the system as needed. Another way is the use of waterfalls, storing it as kinetic energy potential, while absorbing sunlight and storing it in the form of heat, which creates an additional microclimate.

Principle 3 - Income obtained: This is the sum total of surplus energy produced, stored, saved, reused or converted by the system. The created and cultivated ecosystems produce food, shelter, fiber and medicinal crops. Each permaculture design must produce multiple and abundant yields. Thus, a production with abundance in monoculture can be shared with various cultures for greater income in the same area of land.

Principle 4 - Self-regulation and feedback: relates to issues of scale, starting small, getting feedback to redesign gradually. The gradual changes with positive and negative feedback loops minimize the difficult challenges. In the case of domestic animals that feed on plants, they fertilize the land that provides food for flying predators.

Principle 5 - Valuing resources and renewable services: the use of resources that are available locally stimulates the regeneration capacity in short periods of time. For the use of locally available wood for structures has its life in the same proportion of their own regeneration cycle.

Principle 6 - Wastless production: Each by-product of an element is used in the following design. The methane digester captures methane gas generated from human waste, converting it in gas to fuel domestic stoves.

Principle 7 - Detailing design from standards: Evaluation of all materials and energy available before the project planning stage. It requires analysis of the details of the landscape and vegetation before human intervention to determine soil health and culture itself.

Principle 8 - Integration to segregation: mature system of nature has mutual and symbiotic relationships between all your system elements where permaculture designers work to create cooperative relations in all aspects.

Principle 9 - Adoption of simple and slow solutions: the system must be designed to run on a smaller scale features that are practical and efficient in energy consumption. The handling of small scale systems allows measurable changes and avoids punctual faults where the increment project starts from a core and externalizes gradually. Thus you can begin occupying five percent of land with perennial plants with annual increase of five percent leading to a complete overlap of the earth in 10 years

Principle 10 - Value diversity: the greater the diversity of elements in the system, the greater the diversified income. However, the diversity of individual elements does not contribute to the health system, unless the elements are interconnected. It is the diversity of connections that matter, not just the raw diversity elements.

Principle 11 - Use of borders and enhancement of margins: the edge of a forest has more robust trees, and wetlands are rich in biodiversity. Thus, the edges between two systems have a greater range of species and higher productivity than any single system. The project must increase the border between two systems.

Principle 12 - Creative responses to change: adoption of the expected changes of criteria as well as the flexibility to respond to unforeseen changes aiming system stability. Environments in which animals and plants are growing in low power conditions or trees bend in areas where there are strong winds or flooding. The aim of phenomenology is to clarify the essential elements of experiences of the participants without necessarily explaining them. The phenomenological research is naturally mental and not factual. It is therefore not concerned with describing all the properties of anything in particular, but to discover the essential properties of something (CROWELL, 2009, p.10).

However, the natural inclination of phenomenology is far from the development of the theory or towards a specific understanding but tries to identify evidence through the experiences of the participants.

The interview method of qualitative research was appropriate because it was aimed to describe and deliver on core subjects and practical experiences of the participants. The concept was in line with the general task, which was to understand respondents' answers (GANZ, 2002). The interview method is one of the most effective 
means of capturing the stories and experiences of the participants where information is revealed in depth throughout the process.

\section{Population and Sample}

The sample selected for the study was contacted through e-mail and personally by the manager and operational representatives recruited through non-probabilistic intentional sampling in which employees (total five) were invited verbally. Small size samples are suitable for qualitative research as research methodology because of the closeness that exists between the researcher and the population. In fact, in phenomenological research it relies almost exclusively on extensive interviews (three days of duration here) with carefully selected sample of participants (LEEDY e ORMROD, 2010, p.141). The phenomenological method collects information only from the group that experienced the phenomenon. So, long interview processes make it difficult to have a large sample size, because smaller sample sizes are more suitable for more specific research investigations. Sampling is also important for interpretive research because many qualitative studies, if not most, involve generalizations (CRESWELL, 2011). Participants had verbal and written instructions on the study, the explanation of confidentiality protocols and other materials necessary to ensure active participation.

\section{Data collection}

The time and day for the interviews were scheduled at the convenience of participants (NADEN e SAETEREN, 2006). Interviews were conducted locally, free of the influence of food or offices formality. Participants had enough time for a detailed account of their experiences. The interviews ended when the participants indicated that they had nothing to add. Individual differences of the participants influenced the time, in detail and in the interview of intensity during the three days of intense activity. Participants had the option to review the process of interview and follow up, enlightenment, and completion. Self-reflection technique was used in data collection, as a prelude to the initial contact with the participants, in preparation for interviews, and as a step in the data analysis (MOUSTAKAS, 1994; POLKINGHORNE, 1994). Senge (1994) also suggested the same ideas as a means of preparing, analyzing and synthesizing information. Jacques (1996) suggests the reformulation to describe a way of thinking about a concept, an issue or behavior to set idea or situation in different contexts. Along with interviews, there is also the tone, body language, attitude and other communication nuances that were used during practice the concept of escalation (epoche), and leaving aside any prejudices. The scheduling technique helps researchers remain faithful to the participants to report freely and openly their experiences to portray their truths reliably. In the process of narrative research, Creswell (1998) recommends the use of protocols in a prepared spreadsheet with data and information obtained during the interview and observation. To support the identification of field problems, the researcher used a picture as reflective diary technique influenced by CRESWELL (1998), SCHÖN (1987), and JOHNS (1994). The reflective diary has a clear framework to guide the reflections and an artifact that allows critical in-depth analysis including sections such as pre-reflective preparation, reflection, learning and action learning (WALL, GLENN, MITCHINSON e POOLE, 2004). Reflections are also guided through support of technical notes and journals to identify notions and preconceived expectations (GARZA, 2007; MACNEE e MCCABE, 2008).

\section{Presentation and Analysis of Results}

The collected data suggest that practitioners have a deep understanding of natural farming and permaculture related to the technical aspects as well as a deep appreciation of the philosophical "lifestyle" and a holistic understanding of agriculture beyond the experience-based specific technical learning.

Permaculture principle adapted from Brown (2009)

\begin{tabular}{|c|c|}
\hline PRINCIPLES & SUMMARY OF RESPONSES \\
\hline $\begin{array}{l}\text { Henri Bortoft (1996) writes about the } \\
\text { difficulties in understanding, which comes } \\
\text { from the long-standing habit of seeing things } \\
\text { isolated from one another. When things are } \\
\text { viewed on its context, so that the intrinsic } \\
\text { links are revealed, what we have is an } \\
\text { understanding moment. }\end{array}$ & $\begin{array}{l}\text { - I spend a lot more quality time with my } \\
\text { family and cultivating the soil that give us the } \\
\text { nutrients. } \\
\text { - The management of empty spaces of the soil } \\
\text { whose surface is covered by weeds, nitrogen } \\
\text { fixers in soil, which favor the development of } \\
\text { earthworms and } \\
\text { micro-organisms that fertilize the soil } \\
\text { providing harmony in the subsurface. } \\
\text { - The landscape project that is allocated to } \\
\text { intensive hand-labor shows obvious signs of } \\
\text { addiction in humans. } \\
\text { - In a nice and comfortable chair under a } \\
\text { peach or plum tree I concentrate in my } \\
\text { breathing and I focus my attention on my } \\
\text { senses and allow all my organs to absorb and } \\
\text { be absorbed by the landscape. } \\
\text { This way I can understand that everything is } \\
\text { related to each other, and use my imagination } \\
\text { to commune with the inside of the Nature. }\end{array}$ \\
\hline
\end{tabular}




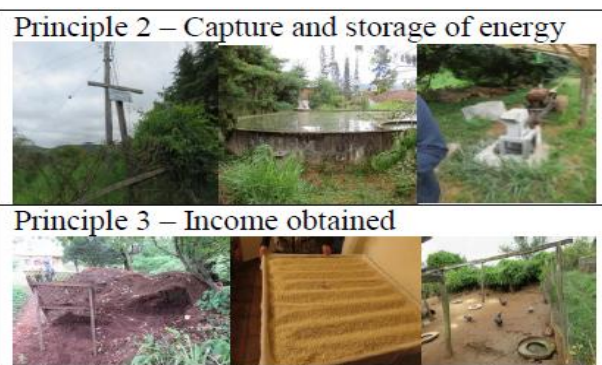

Principle 4 - Self-regulation and feedback

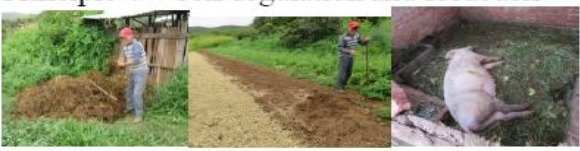

Principle 5 - Valuing resources and renewable services
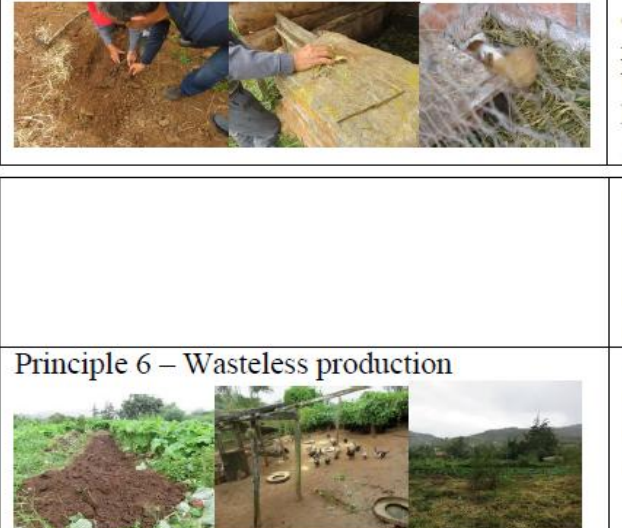

Principle 7 - Detailing design from standards

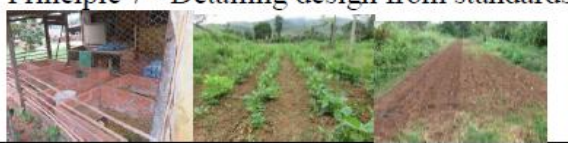

Principle 8 - Integration to segregation

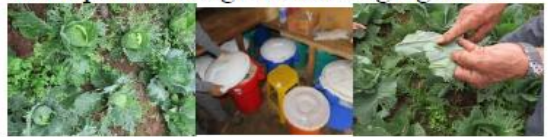

Principle 9 - Adoption of simple and slow solutions

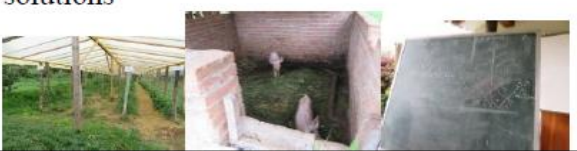

Principle 10 - Value diversity

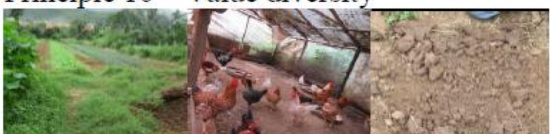

Principle 11 - Use of borders and enhancement of margins

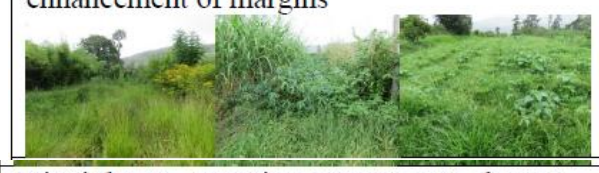

Principle 12 - Creative responses to change

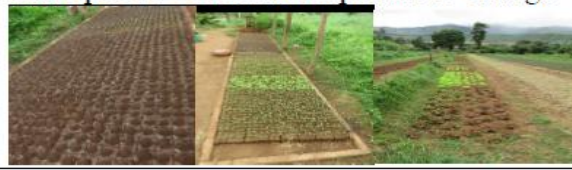

The winding edges allow a natural flow of energy and water storage with distribution of resources. This encourages the creation of areas and surfaces for the plants, water. insects, fish. birds and other animals to interact.

The grain is dried by at least one day and then stored for consumption and sale. Fruits and vegetables are harvested for our own consumption and sale.

Land preparation with $50 \%$ composting and $50 \%$ topsoil with waste of local harvest. Then the seedlings are properly transplanted, so the plants thrive better than by direct sowing (Tomatoes, green beans, eggplants. cucumbers, basil. lettuce, cabbage, okra, beans, chives)

Region devastated by deforestation resulting in improper land, so permaculture enables the creation of a natural habitat for growing food and breeding.

In underground environments, dendritic system of roots creates infinite edges that

make contact with water, nutrients and microorganisms. Similarly, branches and leaves above the ground use edges to achieve high levels of photosynthesis or contact with atmospheric gases.

It requires little input of elements in the system for the resignation of expensive chemicals and consequent reduction of costs, enabling sustainable living.

Valuing of their assets, entrepreneurship and enjoyment of agriculture, reasons to continue operating agriculture and desire to see agriculture as their only occupation.

It allows weeds to integrate with particular vegetables which, in turn, improve the soil quality, because weeds attract microbes and insects allowing a beneficial balance of the ecosystem as well as income of short and long term.

It requires a deep and meticulous exploration plan with data recording and development of a strong system with support through the network and seeking for mentors.

The incorporation of animals as part of the agricultural operations can be seen as a way to increase the value and diversity, for they can cultivate and fertilize the soil before planting and during the crop they feed on insects and help control insect population. Working on a farm is a great way for people who are stressed or depressed to feel full of life and this experience has made them reflect on how much grateful they have to be.

Sowing, germination, speed of germination, transplant, survival rate after transplantation, location in beds, spacing, sharing with other plants, date of bloom/growth, date of the first fruiting and harvest, date of the latest harvest and production. 
It allows the creation of a microclimate and produces many varieties of crops in a small space, reducing pests, thus eliminating the use of pesticides, bringing the importance of eating seasonally and locally, because "it is much better for your body to eat what is in the season". "You cannot be better than nature. " Monoculture is a common practice in most large properties, but natural agriculture "seems to be so wild" and still productive. For biodiversity within an agricultural system with harmonious relationship between plants, animals, insects and microorganisms helps cultivate the land with respect for life and adding value to cooperation rather than competition with nature. Ecological beliefs and desire to live sustainably is to stay closer to nature.

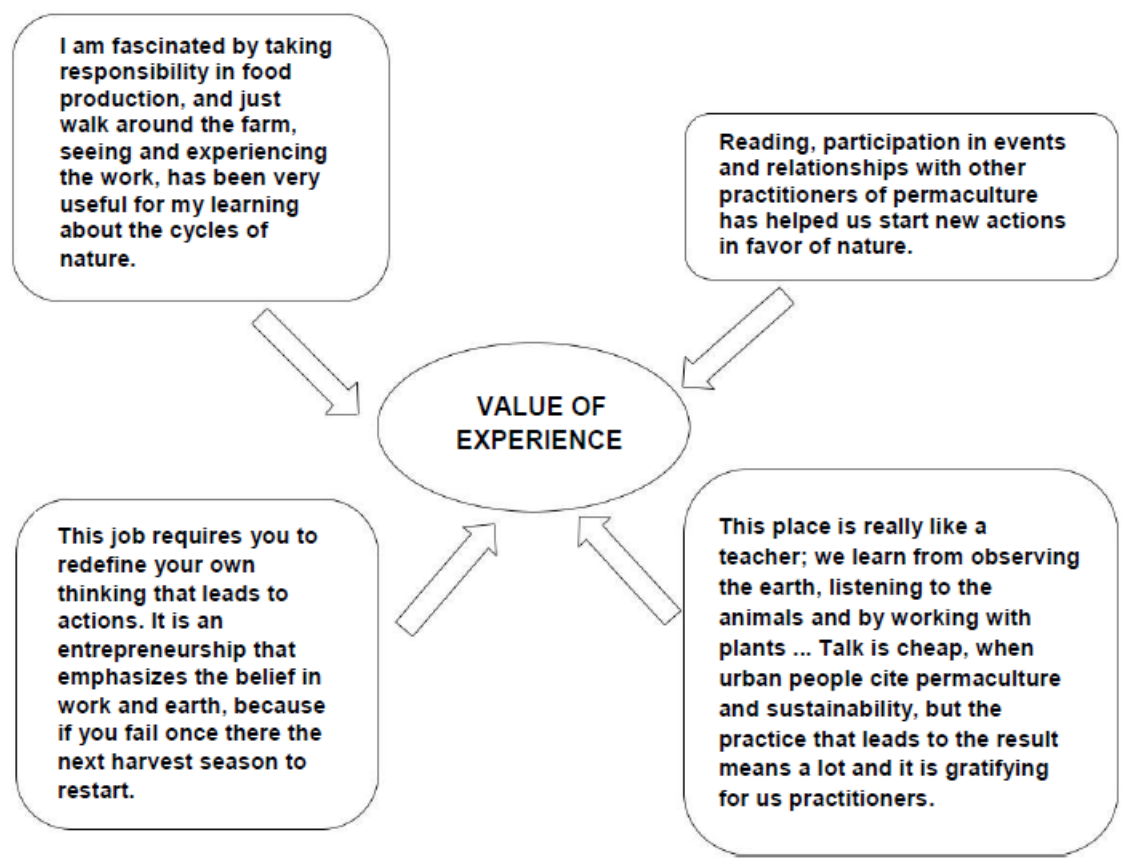

Source: the authors

For the respondents, the practice of permaculture has impacted their individual lives positively and facilitated the integration with local community, building solid ties of socioeconomic relationship where nature seeks to build and benefit. One of the major themes that emerged from interviews, informal conversations and final presentations, where participants voiced their experiments, perception or understanding that generated some kind of significant change on agriculture, on their way of life, or on themselves, was that most were unanimous in indicating changes in consciousness obtained experimentally.

\section{Final Considerations}

In order to adopt sustainable agricultural practices that meet the human needs on a practical scale, we must change the way we view our relationship with the earth and each other. The fundamental transformation of the agricultural system requires a change of perspective and cultural awareness around human interrelations with the natural and the industrial world. It also challenges people to take action in their communities to adopt sustainable agricultural practices that meet the human needs on a practical scale, able to transform the way we view our relationship with the earth and each other.

From this pedagogical framework, we need to explore the complexities of natural ecosystems and manmade: the biomes, watersheds and food silos; political, economic and social forces that shape our lives in the burgeoning field of sustainability in order to critically examine emerging and sometimes conflicting hegemonies. The main themes identified are the value of experience, a balance between theory and practice, the emergence of systems for understanding and technical understanding, connection with nature, and changes in perception about way of life and agriculture. That means, it requires the integration of permaculture principles in an ethical manner in their daily lives. Family, community and safety are factors that influence participants to grow organically, in order to improve their business model, create jobs, become proactive leaders in their communities and pass on their knowledge to posterity for generations to come. The exploitation of permaculture as a socioeconomic model building tool opens the possibility of further research on the role of nature in conflict resolution processes as research field, because there is no extensive literature research, whose academic framework aims at conflict resolution. Finally, in the words of Masanobu Fukuoka (1978), "the ultimate goal of agriculture is not growing crops, but the cultivation and perfection of human beings." 


\section{References}

[1] ANDERSON, M. K. Tending the wild: Native American knowledge and the management of California's natural resources. Berkeley: University of California Press, 2005.

[2] BELL, G., The permaculture way: Practical steps to create a self-sustaining world. White River Junction, VT: Chelsea Green, 2005.

[3] BERKES, F., Sacred ecology: Traditional knowledge and resource management, Philadelphia, PA, 1999

[4] BERRY, W., The unsettling of America: Culture and agriculture. San Francisco, CA: Sierra Club Books, 1977.

[5] BERRY, T., The dream of the earth. San Francisco, CA: Sierra Club Books, 1999.

[6] BORN, B. e PURCELL M. Avoiding the local trap: Scale and food systems in planning research. Journal of Planning Education and Research, 2006

[7] BORTOFT, H. The wholeness of nature: Goethe's way toward a science of conscious participation in nature. Hudson, NY: Lindisfarne Books, 1996.

[8] BUTTEL, F. e FLINN, W. L. Environmental Politics: the structuring of partisan and ideological cleavages in mass environment attitudes, Sociological Quarterly, 1976.

[9] BROWN, Allison, Counting farmers markets, Geographical Review, 2001

[10] CRESWELL, J.W. Research Design: qualitative and quantitative approaches. London: Sage, 2002.

[11] CRESWELL, J. W., Education research: Planning, conducting, and evaluating quantitative and qualitative research. Upper Saddle River, NJ: Prentice Hall, 2008

[12] CRESWELL, J. W., Educational research: Planning, conducting, and evaluating quantitative and qualitative research, Upper Saddle River, NJ: Pearson, 2011.

[13] CAPUTO, V., et all., Food miles or carbon emissions? Exploring labelling preference for food transport footprint with a States Choice Study. The Australian Journal of Agricultural and Resource Economics, 2013.

[14] CAPRA, F., The hidden connections: Integrating the biological, cognitive, and social dimensions of life into a science of sustainability. New York, 2002

[15] CARTER, B.R., PERMACUlTURE: A Designers' Manual, Chelsea Green Publishing, San Francisco, CA, 2014

[16] DILTHEY, W., Introduction to the human sciences: An attempt to lay a foundation for the study of society and history (R. J. Betanzos, Trans.). Detroit: Wayne State University Press, 1883,1988

[17] EDWARDS-JONES, Gareth et. all, Testing the assertion that 'local Food is Best': The challenges of an evidence-based approach. Trends in Food Science \& Technology, 2008. CROTTY, M., The foundations of social research: Meaning and perspective in the research process. Thousand Oaks, CA: Sage, 1988

[18] CROWELL, S., Husserlian phenomenology. In H. L. Dreyfus \& M. A. Wrathall (Eds.), A companion to phenomenology and existentialism (pp. 9-30). West Sussex, UK: Wiley-Blackwell, 2009

[19] GANZ, P. A. (2002). Crosscutting issues in assessing the quality of cancer care. Acesso de http://books.nap.edu/openbook., 2009

[20] GARZA, G., Varieties of phenomenological research at the University of Dallas: An emerging typology. Qualitative Research in Psychology, 2007

[21] GIORGI, A., Concerning variations in the application of the phenomenological method. The Humanistic Psychologist, 2006.

[22] GLIESSMAN, S. Agroecologia: processos ecológicos em agricultura sustentável. Porto Alegre: Editora da Universidade/UFRGS, 2000 .

[23] HANSEN, J. W., Is agricultural sustainability a useful concept? Agricultural Systems, 1996. HEMENWAY, T., Gaia's garden: A guide to homescale permaculture (2nd ed.). White River Junction, VT: Chelsea Green, 2009.

[24] IKERD, J., Building and maintaining sustainable organizations, Organization Management Journal, 2008.

[25] HAWKEN, P., Blessed unrest: How the largest movement in the world came into being and why no one saw it coming. New York, NY, Penguin Books, 2007.

[26] JACQUES, R., Manufacturing the employee: Management knowledge from the 19th to 21st Centuries. Thousand Oaks, CA: Sage Publications Inc, 1996

[27] JOHNS, C., Nuances of reflection, Journal of Clinical Nursing, 1994

[28] LOVELOCK, J., The ages of Gaia: A biography of our living earth. New York, NY, W.W. Norton, 1988.

[29] LOVELOCK, J., Healing Gaia: Practical medicine for the planet. New York, NY, Harmony, 1991. LOVELOCK, J., Gaia: A new look at life on earth. Oxford, England: Oxford University Press., 2000a.

[30] LOVELOCK, J., Homage to Gaia: The life of an independent scientist. New York, NY: Oxford University Press, 2000b.

[31] MACNEE, C. L. e MCCABE, S. Understanding nursing research: Using research in evidence-based practice (2nd ed.). Philadelphia, PA: Lippincott Williams \& Wilkins, 2008 MEA- Millennium Ecosystem Assessment, Ecosystems and human wellbeing: synthesis, Island press, WA, 2005.

[32] MERCHANT, C., Radical ecology: The search for a livable world. New York, NY: Routledge, 2005.

[33] METZNER, R., Green psychology: Transforming our relationship to the Earth. Rochester, VT: Park Street Press, 1999.

[34] MOLLISON, B., Permaculture: A designer's manual. Tyalgum, Australia, Tagari, 1988 MOLLISON, B. e HOLMGREN, D., Permaculture one: A perennial agriculture for human settlements. Tyalgum, Australia: Tagari, 1978.

[35] NABHAN, G. P. e TRIMBLE, S., The geography of childhood: Why children need wild places. Boston, MA: Beacon Press, 1994.

[36] NADEN, D., e SAETEREN, B., Cancer patients' perception of being or not being confirmed,

[37] Nursing Ethics, 2006

[38] PEARSON, C., Regenerative, Semiclosed Systems: A Priority for Twenty-First-Century Agriculture. Bioscience, 2007.

[39] PLOTKIN, B., Soulcraft: Crossing into the mysteries of nature and psyche, New World Library, Novato, CA, 2003.

[40] POLKINGHORNE, D. E. (2005). Language and meaning: Data collection in qualitative Research, Journal of Counseling Psychology, 2005

[41] REDDY KN, HEATHERLY LG, BLAINE A. Weed management. Pages 171-196 in Heatherly LG Hodges HF eds. Soybean Production of the Midsouth. CRC press, 1999 RIETBERGEN, J., Building a sustainable future. Retrieved April; 17, 2012, from WWF Global, 2008

[42] SCHÖN, D., Educating the Reflective Practitioner- Oxford, Jossey-Bass, 1987.

[43] SENGE, P. et all. The necessary revolution: How individuals and organizations are working together to create a sustainable world. New York, NY, 2008

[44] SHELDRAKE, R., The rebirth of nature: The greening of science and god. Rochester, VT: Park Street Press, 1994 http://www.assets.panda.org/downloads/wwf_better_futures_sign_off.pdf

[45] STRAUSS, S. Y. et al., Direct and ecological costs of resistance to herbivory. Trends in Ecology \& Evolution, 2002.

[46] SWIMME, B. e BERRY, T., The Universe Story: From the Primordial Flaring Forth to the Ecozoic Era-A Celebration of the Unfolding of the Cosmos. San Francisco, CA: Harper Collins Publishers, 2002. 
[47] van MANEN, M., Writing qualitatively, or the demands of writing. Qualitative Health Research, 2006.

[48] WALL, C., GLENN, S., MITCHINSON, S., e POOLE, H., Using a reflective diary to develop bracketing skills during a phenomenological investigation. Nurse Researcher, 2004 WILSON, E. O., The future of life. New York, NY: Vintage Books, 2002.

[49] YIN, R. K., Case Study Research Design and Methods (5th ed.). Thousand Oaks, CA: Sage, 2014

[50] YUNLONG, C., e SMIT, B., Sustainabilty in agriculture: A general review, Agriculture, Ecosystems, and Environment, 1994. 